\section{Droga e \\ publicidade: \\ uma visão \\ simbólica}

\section{RESUMO}

As condutas de intoxicação apresentam componentes encontrados como argumentos de venda e de comunicação no quadro do esquema publicitário. Dois chamam atenção: a idéia de conduta de risco para fazer emergir a noção de aventura e 0 recurso às substâncias artificiais para promover um estilo de vida.

\section{ABSTRACT}

Risky behaviour show communicational elements wich we have also found in advertising discourses. Two of them have called our attention: the idea that connects behaviour of risk with toxic consume to appeal to the notion of adventure, and the use of drugs to promote a life style.

\section{PALAVRAS-CHAVE (KEY WORDS)}

- Aventura (adventure)

- Evasão (evasion)

- Intoxicação (intoxication)

\section{HélèneHoudayer*}

IRSA-CRI / Montpellier III
Herbert Marcuse denuncia, em seus escritos sobre o pensamento unidimensional ${ }^{1}$, uma imaginação forçada (onde alternam sentido e sem sentido) que se colocaria à serviço do progresso, para o proveito do progresso técnico e da sua própria lógica. Uma das ferramentas privilegiadas desta dominação situa-se no nível das mídias que traçam o laço imaginário e econômico sob a forma de manipulação das palavras. Propomos aqui trabalhar nesta dimensão, com bastante prudência, a partir do nosso objeto de pesquisa e das suas implicações midiáticas: publicidade e droga. Esta última contém uma parte de violência ao mesmo tempo tangível (ela supõe condutas de risco) e simbólica (as referências e imagens dadas à imaginação) que encontramos nas tendências atuais da publicidade. Certas fórmulas publicitárias nos surpreenderam pelo seu parentesco com as imagens da droga.

Estas desfilam em numerosos slogans publicitários através do prisma das condutas de risco, mas são desprovidas do seu aspecto destruidor para se tornarem sujeitos valorizados e servir de objetos publicitários revisitados pelo imaginário sedutor das drogas. Exporemos brevemente neste artigo os aspectos contidos na simbologia da droga que nos parecem entrar em congruência com nossa temática.

O que procura, então, a publicidade senão seduzir, tentar valorizar o espectador, assim como a imagem diabolizante da droga o faz com seu consumidor? Aí está colocada a proposta que liga as mensagens publicitárias às expressões e à linguagem da droga: o espectador é um consumidor virtual da droga. A publicidade explora seus objetos referindo-se aos símbolos da droga para atingir seus objetivos de sedu- 
ção. A intoxicação não se situa tanto na onda de slogans que desfilam sob nossos olhos e ouvidos, ainda menos no produto, mas diretamente no seio das relações simbólicas que cada um pode tecer quando são evocadas as referências às drogas.

Constatamos, pois, que a publicidade apela às temáticas próximas dos comportamentos de intoxicação graças ao imaginário, na sua versão simbólica. Isto é possível através de uma inscrição corporal e emocional dos sujeitos sobre os temas propostos.

A fim de ilustrar nossa proposta, escolhemos articular nossa reflexão em dois eixos temáticos relacionado à aventura ${ }^{2}$ : as perspectivas do risco e do desafio, características dos ideais de conquista da modernidade; e a embriaguez que reveste a parte emocional característica dos paraísos artificiais.

\section{Desafio}

O uso de estupeficiantes evoca o quadro de uma conduta de risco pelos efeitos que estes induzem sobre o corpo e o psiquismo do indivíduo, colocando-o em perigo (abuso, dependência) e podendo chegar ao desafio mortal (overdose). O risco pode também ser vivido sob a forma de uma aventura, de um jogo, com a morte no quadro de uma ultrapassagem dos limites que inaugura um novo modelo de comportamento. Este novo modelo leva o sujeito além da perspectiva do perigo através da idéia de prestígio (aquele que se ultrapas$\left.\mathrm{sa}^{3}\right)$, que vem a ser, na verdade, um argumento para empreender o risco. Esta problemática é amplamente presente nas mensagens publicitárias. Apresentaremos brevemente a idéia através da temática do desafio.

Consideramos, aqui, o conceito de ris$\mathrm{CO}^{4}$ tal qual foi desenvolvido por Niklas Luhmann ${ }^{5}$ : sendo o risco um elemento exterior que pode ser medido em relação a um conceito de segurança, seja ele revelador de decisões e escolhas (se expor) que implicam um cálculo da parte do indiví- duo e o desenvolvimento de estratégias sociais e individuais. Os comportamentos de risco podem ter, então, valores iniciáticos para os adolescentes. Falar de riscos supõe sua percepção em termos de vantagens e proveitos.

O risco pode revestir as cores do imaginário para exercer um fascínio entre os atores das sociedades modernas. Isto pode acontecer de tal maneira que ele se apresenta como um novo modelo de comportamento onde o vivido e sua apreciação diferem de um sujeito para outro. Neste caso optar pelo risco é engajar-se no mundo. Esse valor simbólico do risco é a panacéia dos comportamentos de intoxicação do ponto de vista sociológico.

O que fazemos sofrer ao corpo, no contexto da iniciação, é marcado pela violência. A violência exercida no momento da iniciação é interpretada por Eugène Enriquez ${ }^{6}$ como a marca da sociedade do indivíduo. Consentir com o sofrimento do corpo é dar meios de pertencer ao corpo social. Corpos, violência e iniciação implicam na idéia de morte. Contudo, não se trata de autodestruição na experiência da droga mas, ao contrário, ganhar em intensidade ao se aproximar da morte: formas de vida aparecem então ${ }^{7}$. O consumo de drogas representa paradigmas dos jogos com a morte, já que o que atrai o adolescente em particular é a experiência do risco e de seus limites. No nível da mensagem publicitária, a imagem simbólica do desafio do consumidor de drogas se enche de emoção alimentando-se nos ideais da conquista.

Esta idéia de conquista nós encontramos, inicialmente, na viagem.

O espírito de aventura se descobre através da maioria das publicidades como uma motivação à viagem:

"Até onde leva o espírito da aventura?

Partir com o espírito de aventura é ir mais além

Ao coração de territórios muitas vezes desconhecidos do grande turismo: 
É viver instantes mágicos frente à beleza absoluta do mundo

E percorrer lugares ainda selvagens

Onde mil pessoas vivem afastadas do tempo que passa.

[...]

Se o espírito de aventura está em você, peça o catálogo..."

A idéia da viagem encarna um pensamento de aventura, mas que toma a forma de um desafio: aquele do distante, por conseqüência, do desconhecido, cujo poder exerce um verdadeiro fascínio, à maneira das plantas mágicas, dotadas de efeitos desejosos e cheios de presságios. É preciso então ousar:

"Hermès, a audácia de escolher seu caminho".

Elf, a energia humana: "Para que serve a aventura humana senão para abrir os caminhos?"

Encontramos aqui o espírito de conquista, cara ao grande impulso da modernidade sob a forma de desafio e de certas exigências como aquelas do empreendimento de ações, do desenvolvimento de iniciativas que são sempre bem acolhidas pela sociedade, mesmo se um risco for necessário no início. O risco simboliza a mudança em uma sociedade que quer progredir e não ficar em atraso em relação às outras.

A mentalidade, em termos de progresso, pode caracterizar esse slogan: produção e consumação respondem a um espírito de empreendimento e de inovação que mexem com o consumidor, mas que o convidam também a fugir.

Na RTL você tem direito ao essencial da vida: a façanha e a imaginação. RTL vai lhe permitir transpor seus limites pessoais. RTL lhe fará, assim, sonhar.

"Sonhar é essencial"

\section{“Ultrapassar-se é essencial"}

As ascensões, incursões e recordes cansam, eles marcam os lugares do excesso, mas, esses últimos, longe de serem batidos, assinalam o fruto de um gasto que dá lucro: bravura e cansaço impulsionam personalidades olimpianas. Poderíamos aproximar esse elemento da noção de despesa de Georges Bataille ${ }^{8}$. O homem, ser de desejo, expande-se em todos os sentidos e consome sua energia excedente sob forma de despêndio dando à vida seu teor efervescente. Trata-se de um universo que não teme gastar para criar, à imagem dos hommes ensauvagés de Serge Moscovici ${ }^{9}$.

É possível ver nesta nova mitologia da aventura um reflexo da obsessão pela segurança que leva numerosos atores a relevar o desafio, a tentar o pior, simbolizando uma espécie de negação social da morte. A preocupação da segurança ligada à nossa sociedade é elemento capital que vai conduzir o aventureiro em direção a uma prática exorcizante, para permitir realçar a significação da existência e sair das práticas cotidianas, menos gloriosas. A vida toma uma nova aparência, o que seria um ganho para a mensagem publicitária.

Uma imprensa aventureira vê amanhecer verdadeiros atores, orgulhosos de mostrar suas esperanças já que a televisão exalta os méritos das grandes travessias e epopéias humanas. Hoje a aventura invadiu também a publicidade e seus projetores se engenham em exaltar o embriagamento de um acontecimento. Assim, o risco, colocado sob o sinal da aventura, adquire significações e valores superiores àquele que vive com ele, sabendo que para a publicidade a aventura pode se resumir àquela que consiste em conduzir um carro:

"Ford Escort (...) para nos tirar da monotonia do cotidiano"

Encontramos aqui a idéia de deslocamento associado à liberdade de movimento com o carro, mas também ao desempe- 
nho e ao lúdico. O automóvel é, neste caso, um dos melhores exemplos. Por trás da certeza de um certo conforto, da prova de uma segurança, esconde-se a embriaguez da velocidade, sinal de sensações fortes, da ultrapassagem de limites, do erotismo; distante do cotidiano.

\section{A Embriaguez}

Os efeitos estimulantes dos produtos e sua capacidade de promover o indivíduo sobre o modo da evasão, da embriaguez hedonista, da vertigem suscitada pelo recurso aos paraísos artificiais guiam nossos propósitos: utilizar a força artificial contida nos psicotrópicos para viver de outra maneira a relação com o outro, sugerir a embriaguez como fio condutor nas mensagens publicitárias.

Eugène Enriquez nos diz que "é na vertigem e na perda total que podemos nos sentir vivos verdadeiramente. A guerra é esta vertigem, mas o jogo, a droga, a corrida de carro, são como o desafio aos deuses $^{\prime \prime 10}$. Assim, é necessário integrar a morte como uma dimensão do vivo. Aliás, é esta mesma perda que é objeto de fascínio, ou ainda, atração pelo vazio, pela vertigem da morte. Frente à nossa sociedade que esgota o mito do progresso, implanta-se o desejo da perda que podemos sentir entre os consumidores de droga.

Em Roger Caillois ${ }^{11}$, as drogas manifestam a corrupção dos princípios do jogo levando à destruição dos atores. $\mathrm{O}$ instinto que comanda o jogo, principalmente para o tóxico, aquele do ilinx (estado de transe e de vertigem procurado), é pervertido pela droga: "pelo embriagamento e intoxicação, a busca de uma vertigem faz na realidade uma crescente irrupção, tão mais extensa e perniciosa que suscita um hábito que empurra constantemente ao limite, a partir do qual provamos a confusão procurada"12. Confusão orgânica que rouba ao toxicômano a capacidade de resistir ao fascínio do vazio. Trata-se, desta vez, de se perder brincando com o risco da morte, que se continua a não apresentar-se como realizável, conserva ao menos sua função social. O acaso e o ilinx traduzem na toxicomania uma espécie de atração assustadora e trágica cuja sedução, para Roger Callois, deve ser neutralizada. Esta mesma sedução que encontramos no universo publicitário, existe no modo do delírio, da alucinação ou ainda da vertigem.

O perfume deYves Saint Laurent chamado Champagne, depois Yves Saint Laurent, e finalmente torna-se Yvresse, para dar conta desta atração.

A vertigem agarra também o consumidor de Perrier:

"Nada vale a ivresse de uma Perrier"

Neste sentido a busca do prazer e da embriaguez pode nos introduzir à uma visão de liberdade que se afirma através do produto proibido, uma maneira de se liberar da prisão sociocultural. A prática de intoxicação coloca em relevo a liberdade de agir do indivíduo frente às regras e normas que ditam sua conduta. Essa necessidade de liberdade é amplamente explorada pela publicidade. $\mathrm{O}$ produto colocado em destaque é uma proposta que permite nos libertar das nossas amarras.

Mas, acima de tudo, o sentimento de querer viver parece juntar-se ao clima ambiente. Este hedonismo parece, através da mensagem publicitária, exprimir-se em pleno dia. Um produto permite suprimir todas as inibições e realizar os sonhos mais loucos.

"O chocolate Crunch desencadeia o cotidiano"

A mensagem publicitária apresenta um aspecto denotativo que se endereça à razão do homem, utilizando o texto e a técnica para convencer sobre as garantias e a segurança de um bom produto. Tal produto contém uma certa porcentagem garanti- 
da em vitaminas, tal outro oferece a segurança em todas as circunstâncias, etc. Mas a maior parte das mensagens combinam um segundo aspecto, este aqui conotativo, que desde então evoca e sugere. A publicidade se direciona à emoção e às motivações inconscientes. A associação de idéias, a evocação de uma imagem, de uma atmosfera ou de uma prática, esta à altura de fornecer o conteúdo afetivo e simbólico do produto.

Os objetos propostos representam símbolos que permitem ao comprador potencial se identificar com um modelo. Estamos próximos de uma caminhada em termos de estilo de vida. Estes estilos de vida parecem-se com símbolos e linguagens, opiniões, atitudes, comportamentos baseados nas motivações dos consumidores, nos seus preconceitos, seus hábitos, mas também sobre seus desejos, suas necessidades de sonhos e de identificações, no relevo do seu ego e dos valores aos quais são apegados. A busca do prazer, de um gozo imediato, se nutre do irracional e do imaginário que encontramos nos produtos tóxicos.

A linguagem publicitária é, neste sentido, próxima à problemática do toxicômano: o prazer absoluto, a busca de sensações fortes, o encantamento. Em suma, encontramos uma problemática própria à droga e ao modo como a apresentamos normalmente.

\section{Opium de Yves Saint Laurent}

Ao mesmo tempo, a mensagem publicitária apresenta os desejos do homem saciado até o esgotamento, até que não termine mais, como um impulso irreparável.

Os produtos dietéticos encarnam uma vontade finalmente satisfeita de consumir sem se privar e ceder à tentação, pois a droga é também isso.

"A publicidade [...] postula um espaço plural, afastado, onde o sujeito tem o sentimento de liberdade de suas escolhas. Seu discurso não é aquele da Verdade, mas aquele da sedução. Sendo assim, se endere- ça exclusivamente ao espaço privado do eu e sua lógica é dissolver o espaço públi$\mathrm{co}^{\prime \prime 13}$. O indivíduo retira a falta ligada a seus desejos nestas imagens que lhe envia a publicidade. E nisso a publicidade, longe de ignorar o universo fantasioso dos sujeitos, interfere no jogo das imagens constituindo a trama dos desejos, mas conservando as normas da sociedade de consumo. De maneira que podemos ver uma cultura ilustrando-se pelos significantes maiores que organizam uma "comunicação institucional". A imagem é promovida como um produto doador de sinais identitários para tornar-se um "discurso social integrador"14.

Certas mensagens são mais explícitas e fazem referência direta à dependência através do produto para se reapropriar de sua simbologia:

\section{"Vocês não podem mais viver sem $\mathrm{O}$ Rustique"}

Aqualand: "dependência da água é uma novidade"

As imagens fazem forte referência ao rito da intoxicação sem darem maiores explicações. O indivíduo está inclinado na direção de uma tábua onde repousa uma placa de vidro com um pó branco. Ele segura na mão uma pequena folha de papel enrolado. $\mathrm{O}$ comentário é o seguinte:

“Experimente logo Iris! Progiciels de gestão Contabilidade-Finança e Pagamento-Recurso"

O vocabulário publicitário faz empréstimo aos códigos da droga.

Enfim, as referências em matéria de intoxicação são portadoras de significações e de evocação capazes de seduzir o consumidor.

"As vitaminas das empresas que ganham"

"IT Comdex o salão que dopa as em- 


\section{presas"}

"Para ganhar,

não tome uma coisa qualquer,

dope antes seu PC"

A publicidade nos mostra, com seu esquema tóxico, como sua caminhada se situa paralelamente à cultura. Ela reflete as normas, as crenças e os sistemas de valores ancorados no social, mas também os desejos e receios dos sujeitos, latentes no imaginário tóxico.

Poderíamos dizer que a publicidade possui uma conivência com os modelos da intoxicação. $\mathrm{O}$ produto proposto deve funcionar tal qual uma droga, a compra pode também ser vivida no quadro de um processo de intoxicação, no qual a mensagem publicitária é levada à consciência de maneira cansativa e repetitiva para obter um ganho.

$\mathrm{O}$ que as mídias transmitem transita por diferentes registros: a emoção, os afetos, a paixão, o medo ou a sedução, que devem muito às imagens e ao som, ficam pertinentes para nossa análise. A problemática da forma foi retomada por Michel Maffesoli que faz referência às diferentes modalidades da aparência, seja a moda, a política, o teatro, a televisão ou a publicidade. Ele insiste sobre a importância do fenômeno através da onipresença da imagem no corpo social ${ }^{15}$. Podemos, assim, observar uma trajetória antropológica que vai da aparência à forma, que permite passar de uma lógica da identidade a uma lógica de identificação.

Na publicidade, o efeito de sugestão é freqüentemente mais forte que aquele da persuasão. A publicidade sugere apenas, nada afirma, e por isso um vocábulo emprestado à droga pode ter um impacto importante.

Ao lado de certas garantias sociais, em termos de segurança e de certeza, se implanta a possibilidade de evadir-se, ultrapassar limites, interditos. A publicidade é um convite perpétuo a derrocar a ordem, porém ela o faz em espaços restritos e virtuais, pela imagem, lá onde tudo é possível. Toda transgressão, mesmo pequena, parece um impulso vital que luta contra a estrutura de encarceramento, como pequenos interstícios deixados à expressão coletiva.

\section{3 esquema publicitário tóxico}

Jean Baudrillard sinaliza que, se antes a sedução dava à imagem negra um desvio, hoje ela marca a ressurreição de tudo que era maldito, o sexo, o desejo, mas também o consumo. A sedução remete à animalidade, não pelo lado da selvageria, prossegue Jean Baudrillard, mas pelo ornamento e pelas formas rituais do encantamento ${ }^{16}$. Para seduzir só é preciso encontrar a regra do jogo, nos diz Baudrillard, pois a comunicação e o social funcionam como uma espécie de pacto em circuito fechado sobre a sedução e o simulacro. É assim que a sedução participa do universo simbólico da droga e da publicidade.

A estética social organiza-se a partir de uma busca de estilo, da importância acordada ao meio ambiente, da valorização do sentimento tribal e de uma dimensão afetiva marcando a prevalescência do sensível ${ }^{17}$.

O imaginário publicitário assegura a conjunção do sonho e da realidade ${ }^{18}$. Podemos aplicar esse principio ao nosso esquema. A presença, sobre o mesmo plano, de horror e fascinação no recurso às drogas é encontrada na publicidade que, por sua vez, utiliza esta imagem para atrair o espectador. O pavor que representa o consumo da droga se transforma em sensações de vertigem. Então, apenas seu caráter emocional conta.

Se olharmos a maneira como a publicidade valoriza os produtos e serviços oferecidos, o repouso, o prazer, a festa e suas sensações vertiginosas estão em cada slogan e nos mergulha em uma nova forma de espetáculo; "último lugar de refração das representações miméticas e estereotípicas. Discurso sem sujeito, sem nome, que se torna a sombra sobre aquela 
se traçam os movimentos das reações afetivas e sociais" ${ }^{\prime 19}$.

Mas não se trata de contentar-se pelo lado contemplativo do materialismo sugerido pelos objetos publicitários; é preciso ultrapassar esta visão de uma sociedade do espetáculo introduzida por Guy Debord ${ }^{20}$, acender as potencialidades virtuais das drogas: sofrer seus efeitos sem lhe experimentar pelo recurso da imagem publicitária.

O espetáculo, por ser, às vezes, impregnado de real e de imaginário, confere as virtudes da transcendência. Lembramos que a transcendência marca o encontro com o sagrado para quem foi tocado por ele. Trans marca um movimento de travessia, enquanto que scando sinaliza a subida. Sem chegar a falar do sagrado na publicidade, fica entendido, entretanto, que as mensagens publicitárias procuram figurar esse impulso em direção ao objeto colocado de frente para tocar a sensibilidade de cada um e de alguma forma interpelar o espectador em suas emoções.

Com isso ela objetiva que o objeto em questão adquira bem mais que seu caráter inicial para beneficiar os aspectos da ordem do sagrado, elemento maior que determinará a escolha de comprar ou se identificar conforme o modelo apresentado pela sociedade. $\mathrm{O}$ apelo ao simbólico da droga contribui para reforçar a impregnância e a eficácia emocional das imagens e objetos publicitários •

\section{Notas}

Texto traduzido do francês por Clélia Pinto

* Professora de Sociologia na Universidade Paul Valéry Montpellier III. Doutora pela Universidade Paris V Sorbonne. Pesquisadora no Institut de Recherches Sociologiques \& Anthropologiques e no Centre de recherches sur l'Imaginaire (IRSA-CRI). Contato: houdayer@sociologie.net

1 MARCUSE, Herbert. L'Homme unidimensionnel. Paris: Minuit, 1968.
2 Cf.as temáticas que proponho no meu livro Le Défi toxique, conduites à risque et figures de l'ivresse. Paris: L'Harmattan, 2000.

3 Cf. CANETTI, Elias. Masse et puissance. Paris: Gallimard, 1966.

40 autor alemão, Ulrich Beck (La Société du risque, Paris, Aubier, 2001 [1986]) fez do risco o conceito mesmo do século, pois ele dá conta de um mundo voltado à individuação crescente impondo ao sujeito cálculos em relação às contingências de sua existência.

5 LUHMANN, Niklas. Risk: a sociological theory. New York: Walter de Griyter, 1993.

6 ENRIQUEZ, Eugène. De la Horde à l'État, essai de psychanalyse du lien social. Paris: Gallimard, 1983.

7 Elias Canetti associa o "instante de sobrevivência" ao "instante de potência". Cf. Elias Canetti, Masse et puissance, op. cit.. Ou ainda o "extrêmo do possível" em Georges Bataille, a ponto que, "o homem avança tanto que não podemos conceber a possibilidade de ir ainda mais longe". Cf. BATAILLE, Georges. La Part Maudite, CEuvres complètes. Paris: Gallimard, 1976, Tome VII.

8 Ibidem.

9 MOSCOVICI, Serge. Hommes domestiques et hommes sauvages. Paris: Union générale d'Édition, 1974.

10 ENRIQUEZ, Eugène. De la Horde à l'État, essai de psychanalyse du lien social, op. cit., p.171..

11 CAILLOIS, Roger. Les Jeux et les hommes. Paris: Gallimard, 1967.

12 Ibid., p. 115.

13 AKOUN, André. La Communication démocratique et son destin. Paris: PUF, 1994, p. 113.

14 Ibid., p. 127.

15 MAFFESOLI, Michel. Au Creux des apparences, pour une éthique de l'esthétique. Paris: Plon, 1990.

16 BAUDRILLARD, Jean. De la Séduction, l'horizon sacré des 
apparences. Paris: Galilée, 1984.

17 MAFFESOLI, Michel. Au Creux des apparences, op. cit.

18 Ibid.

19 JEUDY, Henri-Pierre. La Peur et les médias, essai sur la virulence. Paris: PUF, 1979, p. 37.

20 DEBORD, Guy. La Société du spectacle. Paris: Gallimard, 1992 [1967]. 